\section{$\underset{\substack{\text { hommes } \\ \text { \& migrations }}}{ }$}

\section{Hommes \& migrations}

Revue française de référence sur les dynamiques

migratoires

$1330 \mid 2020$

1973, l'année intense

\title{
Virginie Symaniec, Barnum
}

Ed. Signes et Balises, Paris, 2019, 229 pages, $18 €$.

\section{Marie Poinsot}

\section{(2) OpenEdition \\ 1 Journals}

\section{Édition électronique}

URL : https://journals.openedition.org/hommesmigrations/11708

DOI : 10.4000/hommesmigrations. 11708

ISSN : 2262-3353

\section{Éditeur}

Musée national de l'histoire de l'immigration

\section{Édition imprimée}

Date de publication : 17 juillet 2020

Pagination : 243

ISBN : 978-2-919040-51-3

ISSN : $1142-852 X$

\section{Référence électronique}

Marie Poinsot, "Virginie Symaniec, Barnum », Hommes \& migrations [En ligne], 1330 | 2020, mis en ligne le 01 juillet 2020, consulté le 05 janvier 2023. URL : http://journals.openedition.org/

hommesmigrations/11708; DOI : https://doi.org/10.4000/hommesmigrations.11708 


\section{Barnum. Chroniques}

Virginie Symaniec, Paris, éd. Signes et Balises, 2019, 229 p., $18 €$.

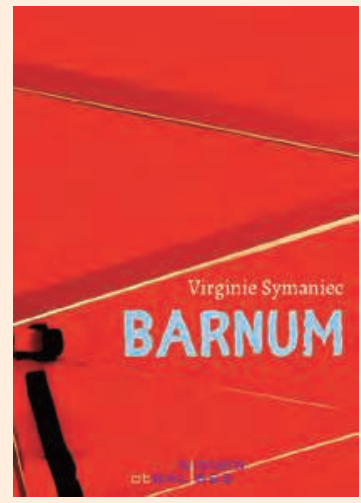

Rouge pétaradant est la couleur de la couverture de ce joli récit personnel, comme le barnum rouge dont l'éditrice indépendante finit par s'équiper sur les marchés locaux où elle vient à la rencontre des gens, surtout ceux qui ne lisent pas, pour les motiver à reprendre ce formidable espace de liberté qu'est le livre. Fidèle à sa ligne éditoriale centrée sur les récits à la première personne, Anne-Laure Brisac a mis son talent d'éditrice (Signes et Balises) pour publier l'essai autobiographique de sa consœur et amie Virginie Symaniec qui, depuis 2013, a fondé la maison d'édition Le ver à soie, après plusieurs années de travaux universitaires en tant qu'historienne et spécialiste de l'histoire du théâtre en Russie et Biélorussie dont est originaire sa famille. "Dans les faits, j'avais besoin d'étudier la Biélorussie pour ne pas être coupée de mes grandsparents. Evelyna, catholique, née à Ixhkodz, et Ouladzimir, fils de Simon, orthodoxe (et oui!) né à Riga, diplômé de l'École polytechnique de vilnius, parlaient entre eux biélorussien; lorsqu'ils travaillaient, ils parlaient polonais; nés dans l'empire des tsars, ils parlaient et avaient fait leurs études en russe. Avec leurs petits-enfants, ils parlent biélorussien. Je vais à l'école de la République et l'on m'y prend pour une Bretonne. » Et cette histoire de l'exil familial, des rituels et des jeux avec son grand-père qui partageait sa maison d'enfance, se dévoile au rythme des saisons et se précipite avec l'annonce hivernale du décès de sa mère.

Ce texte vif, où se mêlent humour et gravité, nous raconte sous la forme de chroniques le dur chemin qui doit être parcouru pour devenir éditrice en France. On partage ainsi au fil des pages ses ambitions, son travail acharné pour que les livres paraissent, les choix de papier, d'illustrations et de format qu'il faut faire avec justesse si l'on veut que les objets livresques épousent au mieux la singularité des contenus éditoriaux. "Dérouler les fils - y compris de la pensée -, les attacher au métier mais aussi toutes les démarches à suivre pour être présente dans les librairies et les salons littéraires, bref le quotidien d'une éditrice, parfois fastidieux mais toujours récompensé quand les ouvrages paraissent à temps et rencontrent un public.»

Comme Virginie Symaniec l'explique, elle décide de créer sa «petite librairie éphémère» en organisant elle-même la diffusion de ses livres sur les marchés ou les salons de terroir, entre des stands de crêpes, ou d'objet artisanaux, par tous les temps et dans toutes les villes ou villages où elle est invitée. Ce défi de «La dame aux livres» est une réponse adaptée à la forte concurrence des distributeurs de libraires mais aussi un combat personnel pour attirer le public vers son stand de livres. Rien ne remplace les discussions au hasard des rencontres improbables entre «celle qui fait les livres» et ceux qui n'osent pas choisir un titre, tenir un ouvrage dans leurs mains, et surtout l'ouvrir.

Elle nous explique comment son catalogue s'enrichit d'année en année avec la littérature adulte axée sur le thème du voyage, de l'exil et du sentiment d'exil, puisant très souvent ses textes dans les littératures d'Europe de l'Est dont elle est originaire et qu'elle a analysé à travers sa première vie d'universitaire, mais aussi à travers une collection de littérature jeunesse et de poésies qui revisitent ces mêmes thèmes en donnant toute sa cohérence à son travail éditorial. On découvre à la fin de son ouvrage une très belle surprise qui, en temps de confinement, fait rêver ceux en mal de nature: elle a collaboré étroitement avec un papetierimprimeur pour mettre en place des poèmes à planter qui reprennent les grands textes sur le voyage (Hugo, Rimbaud, Verlaine, Apollinaire etc.), avec un mode d'emploi pour «poétisez vos peines»: apprendre par cœur le poème, le poser au sol ou dans un pot, le recouvrir d'une fine couche de terre et arroser légèrement tous les jours en récitant le poème, jusqu'à ce que «les pousses de vos mots apparaissent et que vos difficultés se muent en fleurs». Qui pourrait imaginer un présent plus original et précieux à offrir contre le vague à l'âme?

Marie Poinsot 